\title{
A cross-sectional study of the knowledge, attitudes, and behaviors of obstetricians, gynecologists, and dentists regarding oral health care during pregnancy
}

\author{
Jiao Lyü, Xuemei Zhang", Xiaohan Nie, Lin Wei, Huiying He \\ Department of Stomatology, Beijing Tsinghua Changgung Hospital, School of Clinical Medicine, Tsinghua University, Beijing, China \\ Contributions: (I) Conception and design: J Lyu; (II) Administrative support: X Zhang; (III) Provision of study materials or patients: X Nie; (IV) \\ Collection and assembly of data: L Wei; (V) Data analysis and interpretation: H He; (VI) Manuscript writing: All authors; (VII) Final approval of \\ manuscript: All authors. \\ "These authors contributed equally to this work. \\ Correspondence to: Jiao Lyu, PhD. Department of Stomatology, Beijing Tsinghua Changgung Hospital, School of Clinical Medicine, Tsinghua \\ University, No. 168 Litang Road, Changping District, Beijing 102218, China. Email: lvjiao_791@126.com.
}

Background: The aim of this study was to investigate the knowledge, attitudes, and behaviors of Beijing-
based obstetricians, gynecologists, and dentists regarding oral health care during pregnancy and to analyze
their influencing factors.

Methods: Questionnaires drawn from an existing research instrument and modified according to the current situation in China were distributed to obstetricians, gynecologists, and dentists in Beijing by mail or on-site. The questionnaire asked about the participants' knowledge, attitudes, and behaviors regarding oral health care. A $\chi^{2}$ test was used to compare distributional differences of the participants' epidemiological characteristics, and Fisher's exact test was used to calculate the consent rate of consultations for oral health and pregnancy and the safety awareness rate of oral treatment and drug use during pregnancy. Logistic regression analysis was used to study the factors affecting the participants' knowledge of maternal oral health care.

Results: A total of 259 dentists and 146 obstetricians/gynecologists were included in the study. The results showed that $98.61 \%$ of obstetricians and gynecologists and $99.22 \%$ of dentists recognized the importance of oral health care during pregnancy. However, $79.17 \%$ of obstetricians and gynecologists thought they lacked knowledge of oral health care during pregnancy. All obstetricians, gynecologists, and dentists believed that the cost of treatment was one of the main barriers to offering oral health care during pregnancy. Dentists believed that medical disputes were their primary concern. Only a small number of doctors provided oral health care during pregnancy. The results of the logistic regression analysis showed that the professional title of doctor was negatively correlated with knowledge of maternal oral health care.

Conclusions: The findings suggest that there is still a lack of knowledge regarding oral health care during pregnancy, which impacts the attitudes and behaviors of obstetricians, gynecologists, and dentists. Industry authorities should issue unified guidelines to strengthen the continued education of medical staff.

Keywords: Pregnancy; oral health; dentists; obstetricians; gynecologists

Submitted Jul 31, 2020. Accepted for publication Feb 24, 2021.

doi: 10.21037/apm-20-1520

View this article at: http://dx.doi.org/10.21037/apm-20-1520 


\section{Introduction}

Oral health is an important part of general health and affects the whole body. In 2010, the World Health Organization listed it among the ten most important standards of human health (1). However, some physiological changes during pregnancy, such as pregnancy gingivitis, benign oral masses (like pregnancy epulis), gomphiasis, dental erosion, tooth decay, pericoronitis, and periodontitis, may have a negative impact on oral health $(2,3)$. Oral infection during pregnancy not only increases the incidence of preeclampsia, premature delivery, and low infant birth weight $(4,5)$ but also causes the vertical transmission of cariogenic bacteria between mother and fetus (6), resulting in the occurrence of early dental tooth decay in the child. However, many pregnant women do not realize the significance of oral health to themselves and their fetuses and rarely seek the diagnosis and treatment of oral diseases during pregnancy. Previous studies in China have found that only a third of pregnant women have regular oral examinations $(7,8)$. In other developed countries, the proportion of pregnant women using dental services is also low: in the United States only $23-49 \%$ of pregnant women seek oral health care, while, in the United Kingdom and Australia, this figure is 33-64\% and $30.5-33 \%$, respectively (9-12). There are many factors that influence whether a pregnant woman seeks oral health care, including difficulty accessing medical treatment, a lack of awareness of oral health care, lack of understanding of dental treatment during pregnancy, and fear that dental treatment will endanger fetal health. It is therefore important that pregnant women understand the changes to their gums and teeth that occur during pregnancy, strengthen their oral hygiene habits, and treat existing oral problems quickly in order to maintain good oral health during pregnancy and avoid prolonging any oral diseases.

The results of the present study show that the three main sources of oral health knowledge for pregnant women are mass media, advice from medical staff, and the experiences of their friends and relatives. This is slightly at odds with the main ways in which they expect to obtain knowledge: the guidance of medical staff, lectures, and mass dissemination. The results also show that pregnant women most frequently visit an obstetrics and gynecology department where, due to a lack of knowledge regarding oral hygiene during pregnancy, medical staff rarely recommend dental examinations and treatment. Furthermore, dentists often refuse to provide oral treatment services to pregnant women for a variety of reasons.
Previous studies have demonstrated that, while most health care professionals agree on the importance of oral health and acknowledge the need for oral health care during pregnancy, only a few dentists perform general dental care for pregnant women. Furthermore, while obstetricians were found to be more comfortable with their patients undergoing dental procedures during pregnancy but seldom advised pregnant women to visit a dentist (13-15). To date, no study has been conducted in China to evaluate health care providers' perceptions of oral health care during pregnancy.

The present study issued a questionnaire to obstetricians, gynecologists, and dentists in general hospitals, maternal and child health hospitals, stomatological hospitals, and dental clinics in Beijing in order to understand the knowledge, attitudes and behaviors of health care providers regarding the oral health care of pregnant women. The aim of the study was to provide a basis for strengthening the continued education of health care providers, thereby helping them to offer better health care to pregnant women. We present the following article in accordance with the SURGE reporting checklist (available at http://dx.doi. org/10.21037/apm-20-1520).

\section{Methods}

\section{Research subjects}

This study was conducted as a cross-sectional clinical investigation. Between February and June 2019, 300 obstetricians and gynecologists and 300 dentists at Beijing medical institutions (general hospitals, maternal and child health hospitals, stomatological hospitals, and dental clinics) were selected as subjects for cross-sectional investigation using the convenient sampling method.

The study was conducted in accordance with the Declaration of Helsinki (as revised in 2013). The study was approved by ethics board of Beijing Tsinghua Changgung Hospital (No.:19196-0-01) and informed consent was taken from all individual participants.

\section{Research methods}

Researchers who had been trained in a uniform way conducted an anonymous questionnaire by mail and onsite distribution. The survey tool was based on the national consensus statement for oral health care during pregnancy introduced by the National Maternal and Child Oral Health 
Resource Center (OHRC) and on the Pregnant Women Survey questionnaire published (16), which was adjusted to take into account the situation of medical institutions in China and the main purpose of the study (Appendix 1).

\section{Research data}

The main data of the study consisted of participants' basic data and data on oral health and pregnancy, oral health consultations for pregnant women, and oral treatment and drug use among pregnant women. In the questionnaire, the five-point Likert scale (strongly agree, somewhat agree, neither agree/disagree, somewhat disagree, strongly disagree) was adopted for questions regarding oral health and pregnancy and oral health consultations for pregnant women. Questions regarding the frequency of oral care provided by doctors to pregnant women used a scale of "often," "sometimes," "rarely," and "never." Knowledgebased questions were scored based on correct and incorrect answers: a correct answer was given one point, while an incorrect answer was given zero. A total of 20 knowledgebased questions were asked (maximum score 20), and participants were placed into two groups based on their score: group I $(<10)$ failed, while group II $(\geq 10)$ passed.

\section{Statistical analysis}

Fisher's exact test was used to evaluate the awareness rate of respondents regarding questions on oral health and pregnancy and the dental treatment and safety of drug use for pregnant women. A percentage was used to describe respondents' knowledge, attitudes, and behaviors, and a $\chi^{2}$ test was used to compare differences. Logistic regression analysis was conducted to further explore potential influencing factors related to knowledge of oral health during pregnancy.

All statistical analyses were carried out using a two-sided test. $\mathrm{P}<0.05$ was considered statistically significant.

\section{Results}

\section{General data}

A total of 600 questionnaires were sent out, of which 405 were returned (response rate $67.5 \%$ ). Women, staff with a bachelor's degree or higher, staff in public hospitals, and staff with less than 10 years' work experience made up the largest proportion of respondents. The percentage of subjects who had undergone professional training in oral health for pregnant women was relatively low. There were significant differences between dentists and obstetricians and gynecologists in gender, place of practice, number of years of work, number of working hours per week, and opinions on whether training in oral health care for pregnant women should be conducted (all $\mathrm{P}<0.05$, Table 1).

\section{Obstetricians', gynecologists', and dentists' knowledge of oral bealth care during pregnancy}

To investigate obstetricians', gynecologists', and dentists' knowledge of oral health care during pregnancy and the safety of oral treatment for pregnant women, the study proposed five categories of associated knowledge: (I) oral health affects general health; (II) changes in hormone levels during pregnancy increase the risk of periodontal disease in pregnant women; (III) changes in dietary structure and lifestyle habits during pregnancy increase the risk of cavities in pregnant women; (IV) cariogenic bacteria can be transmitted vertically between the mother and fetus; (V) periodontal disease during pregnancy is associated with preeclampsia, premature birth, and low infant birth weight. For (I), (II), and (III), obstetricians, gynecologists, and dentists all demonstrated a good understanding, with the range of correct answers being 91.1-98.84\%. For (IV) and $(\mathrm{V})$, however, the cognitive accuracy of all respondents decreased: the range of correct answers for dentists was $79.15-82.24 \%$, while that of obstetricians and gynecologists was only $44.52-54.79 \%$. The difference was statistically significant $(\mathrm{P}<0.05$, Table 2).

\section{Obstetricians', gynecologists', and dentists' awareness of the safety of oral treatment during pregnancy}

The overall knowledge level of obstetricians, gynecologists, and dentists regarding the safety of dental treatment for pregnant women was low: the rate of correct answers was lower than $50 \%$ in all cases except for the question regarding oral examinations, where dentists achieved a score of $82.24 \%$ and obstetricians and gynecologists achieved a score of $65.07 \%$. Obstetricians, gynecologists, and dentists also placed different emphasis on oral indicators. Regarding basic oral treatments or operations, such as supragingival scaling, subgingival scaling, root surface leveling, singletooth extraction, and nitrous oxide sedation, the cognitive accuracy of obstetricians and gynecologists was significantly 
Table 1 Baseline characteristics of participants

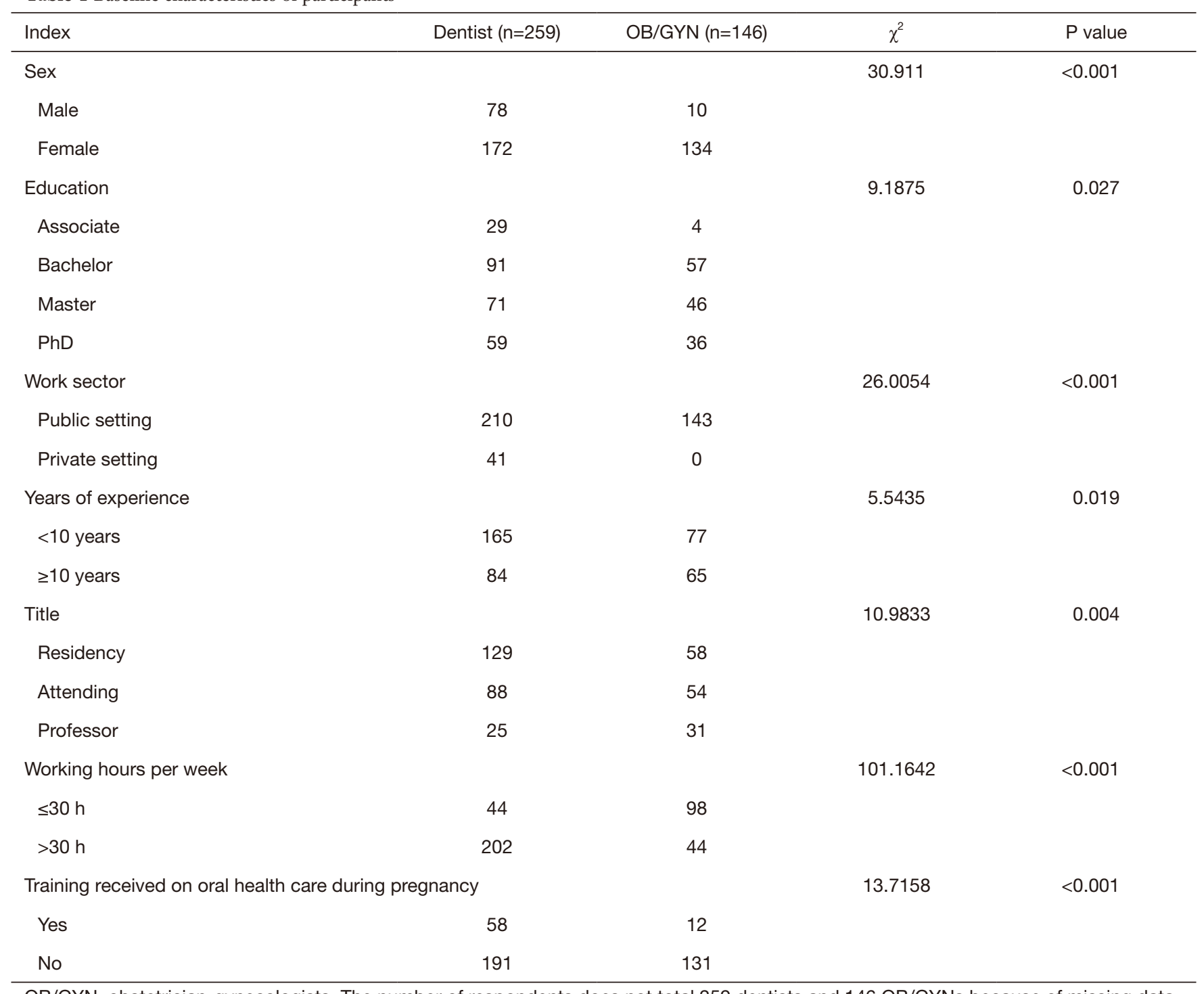

OB/GYN, obstetrician-gynecologists. The number of respondents does not total 259 dentists and 146 OB/GYNs because of missing data.

higher than that of dentists. However, for dental film radiography and other complex oral procedures, including crown repair, abscess incision and drainage, and pulp filling, the cognitive accuracy of dentists was significantly higher than that of obstetricians and gynecologists $(\mathrm{P}<0.05$, Table 3).

\section{Obstetricians', gynecologists', and dentists' attitudes and barriers to offering oral bealth services during pregnancy}

It was found that almost all dentists (99.22\%), obstetricians, and gynecologists $(98.61 \%)$ believed it important to carry out oral health care consultations, including diet consultations, for pregnant women. Furthermore, 99.61\% of dentists and $92.37 \%$ of obstetricians and gynecologists believed that oral health care consultation during pregnancy could improve maternal and infant oral health. A total of $96.85 \%$ of dentists and $88.89 \%$ of obstetricians and gynecologists agreed that advice from obstetricians and gynecologists would improve the willingness of pregnant women to see a doctor for oral health care, and $78.83 \%$ of dentists believed they had the ability to provide oral health care to pregnant women. However, only $57.81 \%$ of dentists believed it was safe for pregnant women to undergo oral treatment, compared to $72.92 \%$ of obstetricians and 
Table 2 Percentage of correct responses to perinatal oral health knowledge

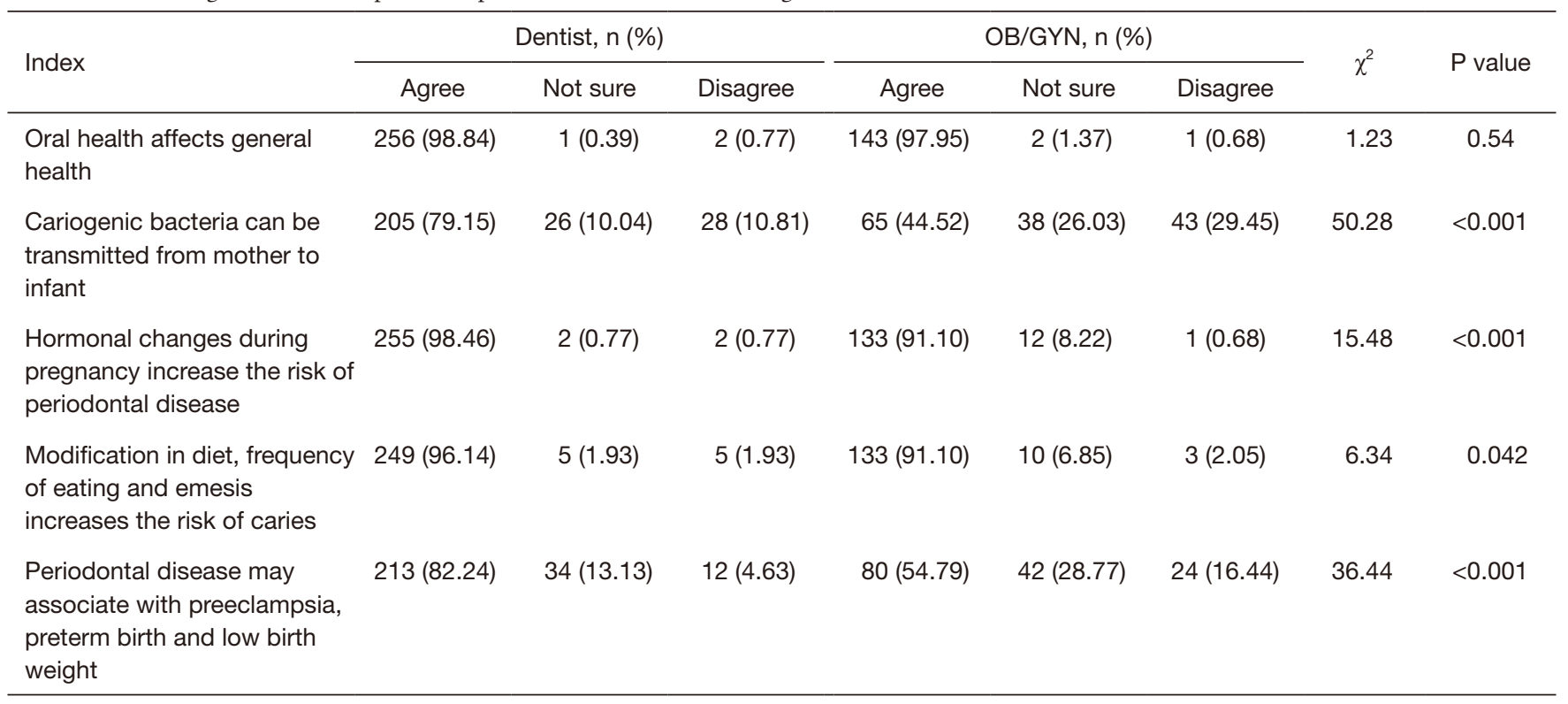

OB/GYN, obstetrician-gynecologists.

Table 3 Percentage of correct responses to dental procedures

\begin{tabular}{|c|c|c|c|c|c|c|}
\hline Dental procedures & \multicolumn{2}{|c|}{ Dentist } & \multicolumn{2}{|c|}{ OB/GYN } & $\chi^{2}$ & $P$ value \\
\hline \multicolumn{7}{|l|}{ Clinic } \\
\hline Oral examination & 213 & 82.24 & 95 & 65.07 & 15.08 & $<0.001$ \\
\hline Prophy & 30 & 11.58 & 48 & 32.88 & 27.16 & $<0.001$ \\
\hline Single periapical X-ray & 43 & 16.6 & 38 & 26.03 & 5.17 & 0.023 \\
\hline Full mouth X-ray \& panoramic radiograph & 17 & 6.56 & 22 & 15.07 & 7.74 & 0.005 \\
\hline Injection of local anesthetics (e.g., lidocaine) & 33 & 12.74 & 36 & 24.66 & 9.36 & 0.002 \\
\hline Single tooth extraction & 9 & 3.47 & 27 & 18.49 & 25.94 & $<.0001$ \\
\hline Crown & 46 & 17.76 & 16 & 10.96 & 3.32 & 0.068 \\
\hline Nitrous oxide & 5 & 1.93 & 12 & 8.22 & 9.16 & 0.003 \\
\hline \multicolumn{7}{|l|}{ Emergency } \\
\hline Single tooth extraction & 23 & 8.88 & 40 & 27.4 & 24.31 & $<0.001$ \\
\hline Injection of local anesthetics & 33 & 12.74 & 47 & 32.19 & 22.23 & $<0.001$ \\
\hline Open and broach & 49 & 18.92 & - & - & & \\
\hline Abscess incision and drainage & 64 & 24.71 & 62 & 42.47 & 13.7 & $<0.001$ \\
\hline Temporary filling & 114 & 44.02 & 43 & 29.45 & 8.32 & 0.004 \\
\hline
\end{tabular}

OB/GYN, obstetrician-gynecologists. 
gynecologists.

Exploration and analysis of the potential barriers to providing oral health care during pregnancy showed that dentists believed the main factors were fear that oral treatment complications in pregnant women would lead to medical disputes $(75.69 \%)$, that obstetricians were more likely to consult on oral health care for pregnant women $(68.75 \%)$, and that the cost of treatment would reduce the willingness of pregnant women to seek it (40.23\%). Obstetricians and gynecologists, however, believed that the main factors were a lack of knowledge of oral health care (79.17\%), that it was the role of dentists to provide oral health care consultations for pregnant women (75.52\%), and that the outpatient department was too busy to offer oral health care to pregnant women $(74.31 \%$, Table 4$)$.

\section{Obstetricians', gynecologists', and dentists' provision of oral bealth care to pregnant women}

While $70.63 \%$ of dentists stated that they had provided oral examinations to pregnant women, only $16.79 \%$ of obstetricians and gynecologists stated that they had. It was stated that dental cleaning was often provided during pregnancy, and about a quarter of dentists said that they had used resin filling for pregnant women. Around $10 \%$ of all respondents stated that they had carried out local anesthesia and root canal therapy on pregnant women, while more than $90 \%$ had never used nitrous oxide sedation during pregnancy (Table 5).

\section{Multivariate logistic regression analysis of obstetricians, gynecologists', and dentists' knowledge of oral health during pregnancy}

The questionnaire included 20 questions related to oral health during pregnancy. Each correct answer was given one point, with a maximum possible score of 20 . The respondents were divided into two categories based on their score: group I $(<10)$ failed, while group II $(\geq 10)$ passed. Using group II $(\geq 10)$ as the dependent variable, binary logistic regression analysis was used to further explore the factors affecting obstetricians, gynecologists', and dentists' knowledge of oral health care for pregnant women.

The results of the univariate analysis showed that the professional title of doctor was negatively correlated with the knowledge of oral health care for pregnant and post-partum women ( $\mathrm{OR}=0.517,95 \% \mathrm{CI}$ : 0.315-0.848). After further adjusting for factors like gender, education level, number of hours worked, number of years of work experience, and whether or not they had received professional training, the correlation was still statistically significant $(\mathrm{OR}=0.444,95 \%$ CI: 0.236-0.836). However, in univariate and multivariate analysis, there was no statistical correlation between the respondents' level of knowledge and their gender, education level, number of hours worked, number of years of work experience, and whether or not they had received professional training.

\section{Discussion}

The results showed that $98.61 \%$ of obstetricians and gynecologists and $99.22 \%$ of dentists recognized the importance of oral health care during pregnancy. However, $79.17 \%$ of obstetricians and gynecologists thought they lacked knowledge of oral health care for pregnant women. All respondents believed that the cost of treatment was one of the main barriers to offering oral treatment to pregnant women, although dentists also believed that medical disputes were a significant barrier. A small number of obstetricians and gynecologists provided oral health care during pregnancy. The results of logistic regression analysis showed that the professional title of doctor was negatively correlated with knowledge of oral health care for pregnant women.

Oral health problems in pregnant women have recently attracted the attention of scholars both in China and abroad. New York, California, OHRC, and the American College of Obstetricians and Gynecologists (ACOG) have released oral health care guidelines during pregnancy and a national census $(17,18)$. The Chinese census data projections in 2010 stated that there would be around 346 million women of childbearing age in China by 2018 and that around 16 million women of childbearing age would be pregnant each year. The theme of 2016's Dental Day in China was "Oral Health, General Health," which advocated paying attention to oral health care throughout life. Its first slogan was "Mom stays away from dental disease and gives birth to a healthy baby." The National Health Commission of the People's Republic of China issued the Oral Health Action Programme [2019-2025] and emphasized that oral health services should cover the whole population and the whole life cycle. Oral health knowledge is also a key part of the pre-marital physical examination, maternal health management, and the pregnant women's school curriculum. Obstetricians, gynecologists, and dentists therefore all play a key role in preventing oral disease and encouraging the 
Table 4 attitude and barriers for oral health care of pregnant patients

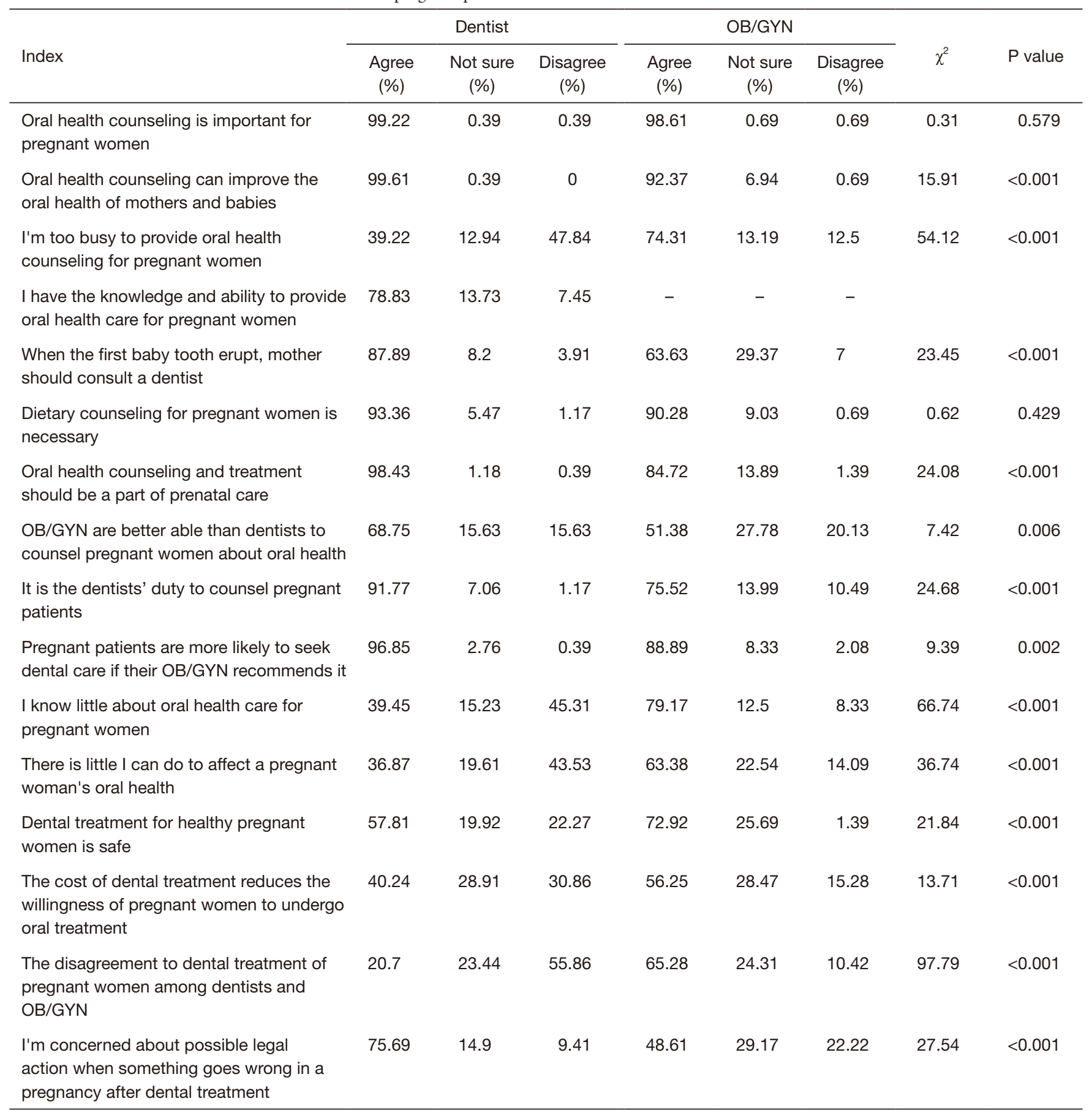

OB/GYN, obstetrician-gynecologists.

oral hygiene education of pregnant women.

The present study is the first in China to examine dentists', obstetricians', and gynecologists' knowledge, attitudes, and behaviors regarding oral health care for pregnant women. The results of the study found that the knowledge level of dentists with respect to oral health was significantly higher than that of obstetricians and gynecologists. Only around half of obstetricians 
Table 5 Frequency of perinatal oral health practices

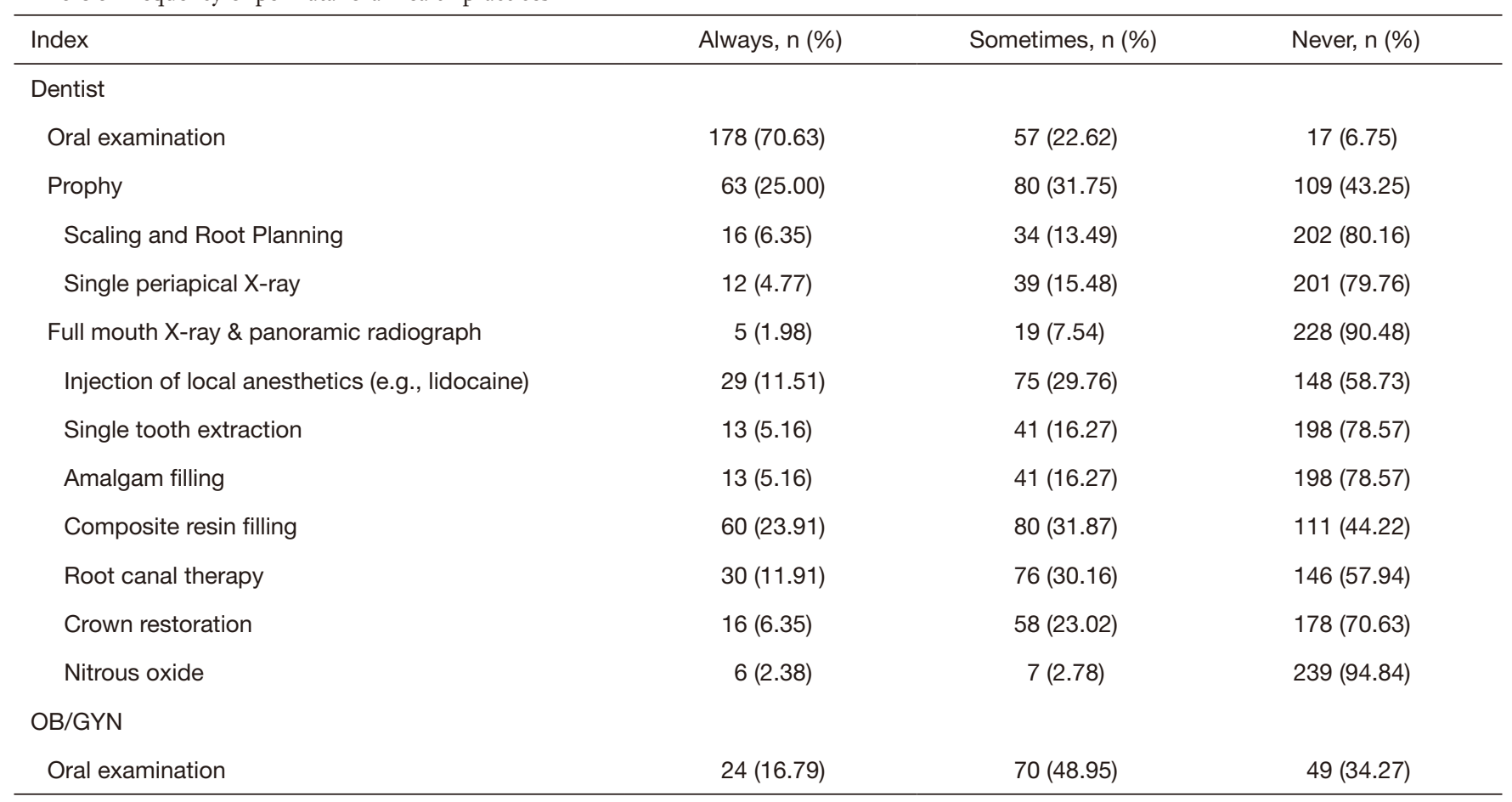

OB/GYN, obstetrician-gynecologists.

and gynecologists correctly answered the questions on knowledge categories (IV) and (V) ("cariogenic bacteria can be transmitted vertically from mother to child" and "periodontal disease during pregnancy is related to preeclampsia, premature birth, and low infant birth weight"). Almost all obstetricians and gynecologists (98.61\%) and dentists (99.22\%) agreed on the importance of oral health care during pregnancy. The results of this study are similar to those of studies from the United States and Australia (13-15,19,20).

In the present study, $79.17 \%$ of obstetricians and gynecologists stated that they felt they lacked knowledge of oral health care for pregnant women, which was the most significant barrier to them providing oral health care services to pregnant women. For dentists, medical disputes were their primary concern. All respondents agreed that the cost of treatment was one of the main barriers to offering oral treatment to pregnant women. Similarly, an American study found that insurance payments and the cost of oral health care were common reasons for patients avoiding visiting a doctor of stomatology; the same study also found that doctors were unwilling to provide oral health treatment to pregnant women (13).

In the present study, respondents' knowledge level regarding the safety of oral treatment for pregnant women was very low. Dentists gave more conservative estimates of the level of safety, while obstetricians and gynecologists were less concerned about medical risks, possibly because obstetricians and gynecologists understand the overall condition of pregnant women and assess the risk of disease more accurately. Obstetricians and gynecologists also provided more counseling and referrals. Therefore, oral treatment, which has a high clinical risk, was greatly reduced.

Regarding the provision of oral treatment to pregnant women, most of the dentists interviewed in the present study were limited in the extent to which they provided oral examinations to pregnant women $(70.63 \%)$. Very few obstetricians and gynecologists provided oral treatment, such as cleaning, local anesthesia, and root canal therapy, to pregnant women. The proportion of comprehensive oral health care for pregnant women in this survey was much lower than that of previous surveys: a study conducted in North Carolina, U.S., showed that $48.3 \%$ of the subjects were provided with more comprehensive dental services (15).

In order to understand the factors affecting dentists', obstetricians', and gynecologists' knowledge of oral health 
care for pregnant and post-partum women in this study, logistic regression analysis was carried out. This identified a negative correlation between the professional title of doctor and knowledge of oral health care for pregnant and post-partum women ( $\mathrm{OR}=0.517,95 \% \mathrm{CI}$ : 0.315-0.848). This correlation highlights the importance of continued education on oral health care for pregnant women.

\section{Conclusions}

The study showed that there is still a lack of knowledge of oral health care for pregnant women in China, which influences the attitudes and behaviors of dentists, obstetricians, and gynecologists. One of the reasons for this lack of knowledge could be that there are few relevant treatment norms in the sector and that medical staff consider the medical risks of oral treatment more carefully, with most doctors adopting a "stay away" approach towards the treatment of oral diseases in pregnant women. As such, it is suggested that basic and continued education on oral health care for pregnant women should be strengthened for dentists, obstetricians, and gynecologists, which would reduce the occurrence of oral diseases and establish oral health management during pregnancy. Another recommendation is to increase social security support and medical insurance for pregnant women's oral treatment in order to reduce medical and patient costs. Relevant authorities may also be able to increase awareness of oral health care during pregnancy and improve treatment practices by issuing unified treatment guidelines as soon as possible.

\section{Acknowledgments}

Funding: None.

\section{Footnote}

Reporting Checklist: The authors have completed the SURGE reporting checklist. Available at http://dx.doi. org/10.21037/apm-20-1520

Data Sharing Statement: Available at http://dx.doi. org/10.21037/apm-20-1520

Conflicts of Interest: All authors have completed the ICMJE uniform disclosure form (available at http://dx.doi. org/10.21037/apm-20-1520). The authors have no conflicts of interest to declare.

Ethical Statement: The authors are accountable for all aspects of the work in ensuring that questions related to the accuracy or integrity of any part of the work are appropriately investigated and resolved. The study was conducted in accordance with the Declaration of Helsinki (as revised in 2013). The study was approved by ethics board of Beijing Tsinghua Changgung Hospital (No.:19196-0-01) and informed consent was taken from all individual participants.

Open Access Statement: This is an Open Access article distributed in accordance with the Creative Commons Attribution-NonCommercial-NoDerivs 4.0 International License (CC BY-NC-ND 4.0), which permits the noncommercial replication and distribution of the article with the strict proviso that no changes or edits are made and the original work is properly cited (including links to both the formal publication through the relevant DOI and the license). See: https://creativecommons.org/licenses/by-nc-nd/4.0/.

\section{References}

1. Petersen PE. World Health Organization global policy for improvement of oral health-World Health Assembly 2007. Int Dent J 2008;58:115-21.

2. Kobylińska A, Sochacki-Wójcicka N, Dacyna N, et al. The role of the gynaecologist in the promotion and maintenance of oral health during pregnancy. Ginekol Pol 2018;89:120-4.

3. Liwei Z, Jing Z, Yong Y, et al. Management of oral diseases during pregnancy. Hua Xi Kou Qiang Yi Xue Za Zhi 2017;35:113-8.

4. Boggess KA. Maternal oral health in pregnancy. Society for Maternal-Fetal Medicine. Obstet Gynecol 2008;111:976-86.

5. Odermatt T, Schötzau A, Hoesli I. Oral Health and Pregnancy - Patient Survey using a Questionnaire. Z Geburtshilfe Neonatol 2017;221:180-6.

6. Basha S, Shivalinga Swamy H, Noor Mohamed R. Maternal Periodontitis as a Possible Risk Factor for Preterm Birth and Low Birth Weight--A Prospective Study. Oral Health Prev Dent 2015;13:537-44.

7. Kashetty M, Kumbhar S, Patil S, et al. Oral hygiene status, gingival status, periodontal status, and treatment needs 
among pregnant and nonpregnant women: A comparative study. J Indian Soc Periodontol 2018;22:164.

8. Chawla RM, Shetiya SH, Agarwal DR. Knowledge, Attitude, and Practice of Pregnant Women regarding Oral Health Status and Treatment Needs following Oral Health Education in Pune District of Maharashtra A Longitudinal Hospital-based Study. J Contemp Dent Pract 2017;18:371-7.

9. Dasanayake AP, Gennaro S, Hendricks-Muñoz KD, et al. Maternal periodontal disease, pregnancy, and neonatal outcomes. MCN Am J Matern Child Nurs 2008;33:45-9.

10. Thomas NJ, Middleton PF, Crowther CA. Oral and dental health care practices in pregnant women in Australia: A postnatal survey. BMC Pregnancy Childbirth 2008;8:13.

11. George A, Ajwani S, Bhole S, et al. Promoting perinatal oral health in South-Western Sydney: A collaorative approach. J Dent Res 2010;89:142301.

12. Hullah E, Turok Y, Nauta M, et al. Self-reported oral hygiene habits, dental attendance and attitude to dentistry during pregnancy in a sample of immigrant women in North London. Arch Gynecol Obstet 2008;277:405-9.

13. Strafford KE, Shellhaas C, Hade EM. Provider and patient perceptions about dental care during pregnancy. J Matern Fetal Neonatal Med 2008;21:63-71.

14. George A, Dahlen HG, Reath J, et al. What do antenatal care providers understand and do about oral health

Cite this article as: Lyu J, Zhang X, Nie X, Wei L, He H. A cross-sectional study of the knowledge, attitudes, and behaviors of obstetricians, gynecologists, and dentists regarding oral health care during pregnancy. Ann Palliat Med 2021;10(4):42424251. doi: 10.21037/apm-20-1520 care during pregnancy: a cross-sectional survey in New South Wales, Australia. BMC Pregnancy Childbirth 2016;16:382-92.

15. Da Costa EP, Lee JY, Rozier RG, et al. Dental care for pregnant women: an assessment of North Carolina general dentists. JADA 2010;141:986-94.

16. Oral Heallth Care During Pregnancy Expert Workgroup. Oral Health Care During Pregnancy: A National Consensus Statement. Washington, DC: National Maternal and Child Oral Health Resource Center, 2012.

17. California Dental Association Foundation; American College of Obstetricians and Gynecologists, District IX. Oral health during pregnancy and early childhood: evidence-based guidelines for health professionals. J Calif Dent Assoc 2010;38:391-440.

18. American College of Obstetricians and Gynecologists Women's Health Care Physicians; Committee on Health Care for Underserved Women. Committee Opinion No. 569: oral health care during pregnancy and through the lifespan. Obstet Gynecol 2013;122:417-22.

19. Huebner CE, Milgrom P, Conrad D, et al. Providing dental care to pregnant patients: a survey of Oregon general dentists. JADA 2009;140:211-22.

20. Curtis M, Silk HJ, Savageau JA. Prenatal Oral Health Education in U.S. Dental Schools and Obstetrics and Gynecology Residencies. J Dent Educ 2013;77:1461-8. 


\section{Appendix 1}

\section{Questionnaire of oral health care during pregnancy}

\section{Demographics}

1.1 Gender: 1. Male 2. Female

1.2 Workplace:

1.3 Age:

1.4 Occupation: 1. Obstetrician 2.Gynecologist 3.Midwife 4. Assistant

1.5 Time in practice: Years

\section{Oral Health and Pregnancy}

\begin{tabular}{|c|c|c|c|c|c|}
\hline & $\begin{array}{l}\text { Strongly } \\
\text { Agree }\end{array}$ & $\begin{array}{l}\text { Somewhat } \\
\text { Agree }\end{array}$ & $\begin{array}{l}\text { Neither Agree/ } \\
\text { Disagree }\end{array}$ & $\begin{array}{l}\text { Somewhat } \\
\text { Disagree }\end{array}$ & $\begin{array}{l}\text { Strongly } \\
\text { Disagree }\end{array}$ \\
\hline Oral health can affect systemic health. & 1 & 2 & 3 & 4 & 5 \\
\hline $\begin{array}{l}\text { Hormonal changes in pregnant women increase their risk } \\
\text { of gum disease. }\end{array}$ & 1 & 2 & 3 & 4 & 5 \\
\hline $\begin{array}{l}\text { Periodontal disease may increase preterm birth, } \\
\text { preeclampsia and low birth weight. }\end{array}$ & 1 & 2 & 3 & 4 & 5 \\
\hline
\end{tabular}

\section{Counseling Pregnant Patients}

\begin{tabular}{|c|c|c|c|c|c|}
\hline & $\begin{array}{l}\text { Strongly } \\
\text { Agree }\end{array}$ & $\begin{array}{l}\text { Somewhat } \\
\text { Agree }\end{array}$ & $\begin{array}{l}\text { Neither Agree/ } \\
\text { Disagree }\end{array}$ & $\begin{array}{l}\text { Somewhat } \\
\text { Disagree }\end{array}$ & $\begin{array}{l}\text { Strongly } \\
\text { Disagree }\end{array}$ \\
\hline $\begin{array}{l}\text { Counseling pregnant women about oral health is } \\
\text { important. }\end{array}$ & 1 & 2 & 3 & 4 & 5 \\
\hline $\begin{array}{l}\text { Counseling a pregnant woman about oral health can } \\
\text { improve the oral health of her baby. }\end{array}$ & 1 & 2 & 3 & 4 & 5 \\
\hline I have the knowledge to counsel pregnant patients. & 1 & 2 & 3 & 4 & 5 \\
\hline $\begin{array}{l}\text { A pregnant woman should be counseled to have a dental } \\
\text { visit when their baby's first baby tooth erupt. }\end{array}$ & 1 & 2 & 3 & 4 & 5 \\
\hline $\begin{array}{l}\text { It is necessary to counsel pregnant patients about their } \\
\text { diet. }\end{array}$ & 1 & 2 & 3 & 4 & 5 \\
\hline $\begin{array}{l}\text { OB/GYN are better able than dentists to counsel pregnant } \\
\text { patients about oral health. }\end{array}$ & 1 & 2 & 3 & 4 & 5 \\
\hline It is the dentists'duty to counsel pregnant patients. & 1 & 2 & 3 & 4 & 5 \\
\hline $\begin{array}{l}\text { Pregnant patients are more likely to seek dental care if } \\
\text { their OB/GYN recommends it. }\end{array}$ & 1 & 2 & 3 & 4 & 5 \\
\hline $\begin{array}{l}\text { There is little I can do to affect a pregnant woman's oral } \\
\text { health. }\end{array}$ & 1 & 2 & 3 & 4 & 5 \\
\hline It's safe to provide dental treatment to a pregnant woman. & 1 & 2 & 3 & 4 & 5 \\
\hline
\end{tabular}




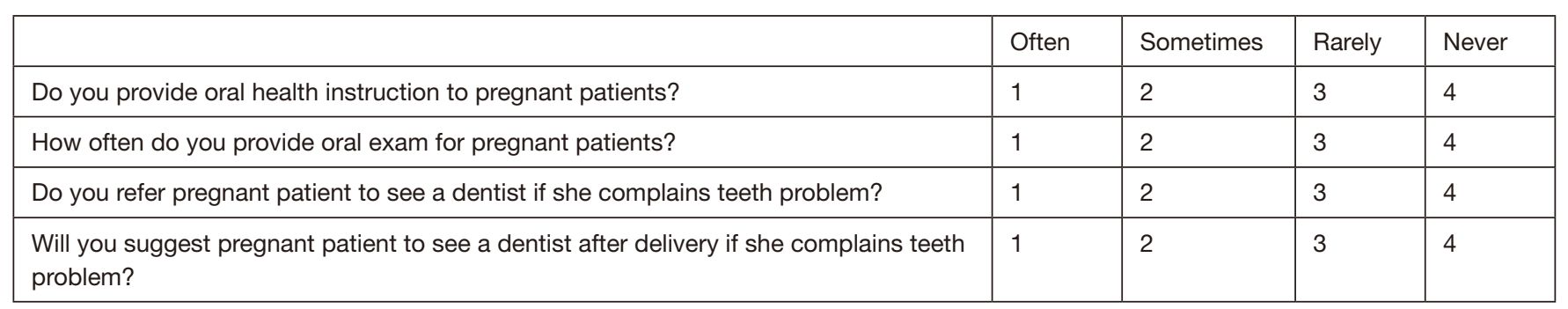

\section{Dental Treatment during Pregnancy}

During which period of pregnancy do you believe it is appropriate to provide each of the following services?

\begin{tabular}{|c|c|c|c|c|c|}
\hline Routine & Anytime during pregnancy & $1^{\text {st }}$ Trimester & $2^{\text {nd }}$ Trimester & $3^{\text {rd }}$ Trimester & Never \\
\hline Prophy & 1 & 2 & 3 & 4 & 5 \\
\hline Scaling and root planning & 1 & 2 & 3 & 4 & 5 \\
\hline Single periapical x-ray & 1 & 2 & 3 & 4 & 5 \\
\hline Injection of local anesthetic (e.g., lidocaine) & 1 & 2 & 3 & 4 & 5 \\
\hline Single tooth extraction & 1 & 2 & 3 & 4 & 5 \\
\hline Amalgam restoration & 1 & 2 & 3 & 4 & 5 \\
\hline Composite restoration & 1 & 2 & 3 & 4 & 5 \\
\hline Nitrous oxide and oxygen sedation & 1 & 2 & 3 & 4 & 5 \\
\hline Emergency & Anytime during pregnancy & $1^{\text {st }}$ Trimester & $2^{\text {nd }}$ Trimester & $3^{\text {rd }}$ Trimester & Never \\
\hline Single tooth extraction & 1 & 2 & 3 & 4 & 5 \\
\hline Injection of local anesthetic & 1 & 2 & 3 & 4 & 5 \\
\hline Incision and graining and abcess & 1 & 2 & 3 & 4 & 5 \\
\hline Temporary filling & 1 & 2 & 3 & 4 & 5 \\
\hline
\end{tabular}

Do you believe it can be used safely during pregnancy with indication and supervision?

\begin{tabular}{|l|l|l|l|}
\hline Analgesics & Anytime during pregnancy & Short duration & Never \\
\hline Acetaminophen & 1 & 2 & 3 \\
\hline Non-steroidal, anti-inflammatory agents, NSAIDS (e.g., Ibuprofen) & 1 & 2 & 3 \\
\hline Antibiotics & Anytime during pregnancy & Short duration & Never \\
\hline Amoxicillin & 1 & 2 & 3 \\
\hline Cephalosporins & 1 & 2 & 3 \\
\hline Clindamycin & 1 & 2 & 3 \\
\hline Metronidazole & 1 & 1 & 2 \\
\hline Ciprofloxacin & 1 & 3 \\
\hline
\end{tabular}




\begin{tabular}{|l|l|l|l|}
\hline Levofloxacin & 1 & 2 & 3 \\
\hline Moxifloxacin & 1 & 2 & 3 \\
\hline Clarithromycin & 1 & 2 & 3 \\
\hline Tetracycline & 1 & 2 & 3 \\
\hline Anesthetic & Anytime during pregnancy & Short duration & Never \\
\hline Local anesthetics with epinephrine (e.g., lidocaine) & 1 & 2 & 3 \\
\hline Nitrous oxide (30\%) & 1 & 2 & 3 \\
\hline Antimicrobials & Anytime during pregnancy & Short duration & Never \\
\hline Chlorhexidine (Without alcohol) & 1 & 2 & 3 \\
\hline Xylitol & 1 & 2 & 3 \\
\hline
\end{tabular}

*Short duration: 48-72 hours

\section{Education and Information}

\begin{tabular}{|c|c|c|c|c|c|}
\hline & $\begin{array}{l}\text { Strong } \\
\text { Agree }\end{array}$ & $\begin{array}{l}\text { Somewhat } \\
\text { Agree }\end{array}$ & $\begin{array}{l}\text { Neither } \\
\text { Agree/Disagree }\end{array}$ & $\begin{array}{l}\text { Somewhat } \\
\text { Disgree }\end{array}$ & $\begin{array}{l}\text { Strongly } \\
\text { Disagree }\end{array}$ \\
\hline $\begin{array}{l}\text { Interdisciplinary approach between OB/GYN and dentist } \\
\text { should be built }\end{array}$ & 1 & 2 & 3 & 4 & 5 \\
\hline $\begin{array}{l}\text { Information about a Continuing Ed program on care for } \\
\text { pregnant patients is needed }\end{array}$ & 1 & 2 & 3 & 4 & 5 \\
\hline
\end{tabular}

\section{Questionnaire of oral health care during pregnancy}

\section{Demographics}

1.1 Gender: 1.Male 2.Female

1.2 Workplace:

1.3 Age:

1.4 Major: 1. General dentist 2. Endodontist 3. Periodontist 4. Oral Surgeon 5. Pediatric dentist 6. Prothodontist 7. Orthodontist 8. Dental Assistant 9. Dental hygienist 9. others

1.5 Time in practice: Years

\section{Oral Health and Pregnancy}

\begin{tabular}{|c|c|c|c|c|c|}
\hline & $\begin{array}{l}\text { Strongly } \\
\text { Agree }\end{array}$ & $\begin{array}{l}\text { Somewhat } \\
\text { Agree }\end{array}$ & $\begin{array}{l}\text { Neither Agree/ } \\
\text { Disagree }\end{array}$ & $\begin{array}{l}\text { Somewhat } \\
\text { Disagree }\end{array}$ & $\begin{array}{l}\text { Strongly } \\
\text { Disagree }\end{array}$ \\
\hline Oral health can affect systemic health. & 1 & 2 & 3 & 4 & 5 \\
\hline $\begin{array}{l}\text { Bacteria that causes caries is transmissible from mother to } \\
\text { baby. }\end{array}$ & 1 & 2 & 3 & 4 & 5 \\
\hline $\begin{array}{l}\text { Hormonal changes in pregnant women increase their risk } \\
\text { of gum disease. }\end{array}$ & 1 & 2 & 3 & 4 & 5 \\
\hline $\begin{array}{l}\text { Modification in diet, frequency of eating and emesis can } \\
\text { increase the risk of developing caries. }\end{array}$ & 1 & 2 & 3 & 4 & 5 \\
\hline $\begin{array}{l}\text { Periodontal disease may increase preterm birth, } \\
\text { preeclampsia and low birth weight. }\end{array}$ & 1 & 2 & 3 & 4 & 5 \\
\hline
\end{tabular}




\section{Counseling Pregnant Patients}

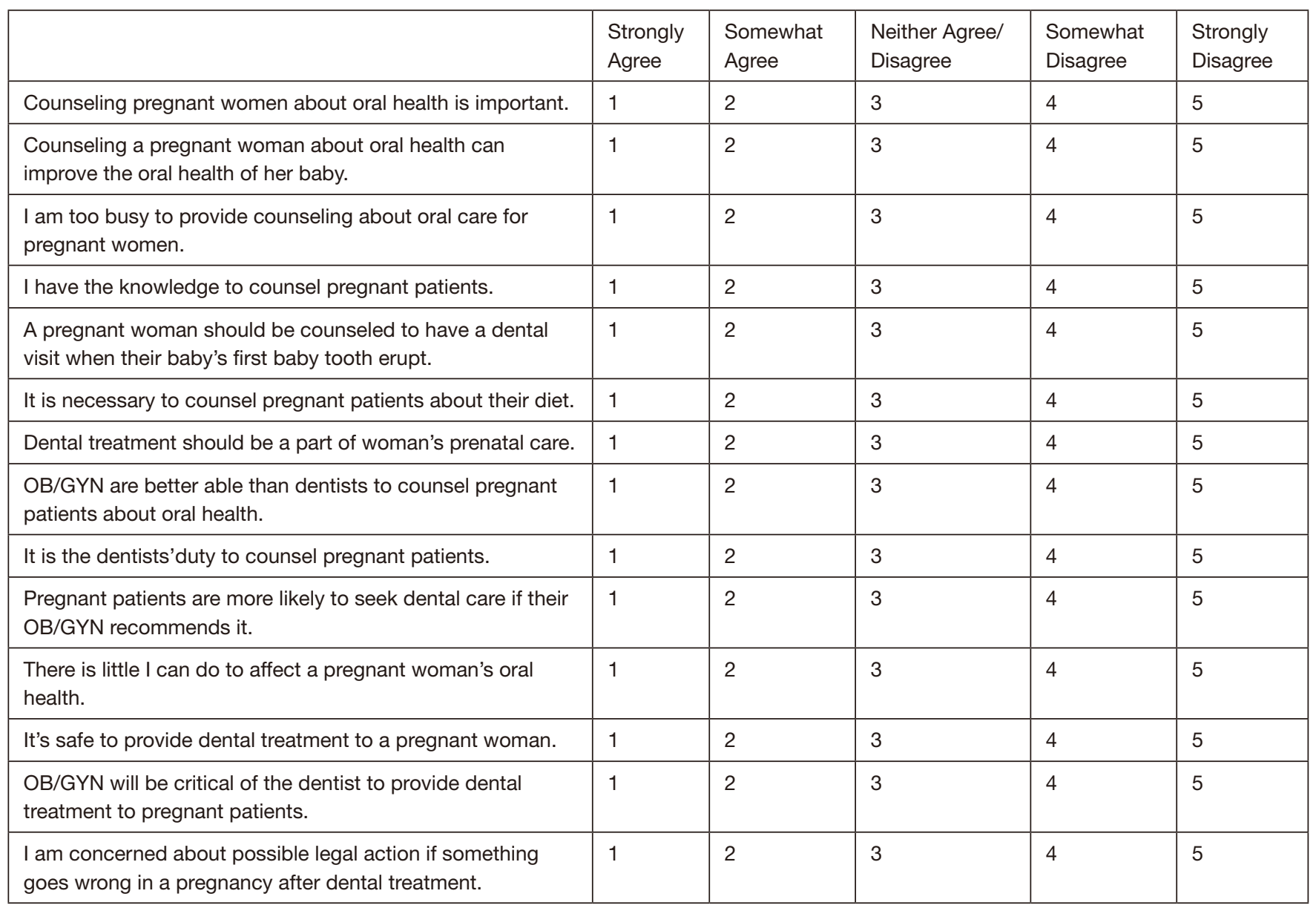

\section{Dental Treatment during Pregnancy}

During which period of pregnancy do you believe it is appropriate to provide each of the following services?

\begin{tabular}{|l|l|l|l|l|l|}
\hline Routine & Anytime during pregnancy & $1^{\text {st }}$ Trimester & $2^{\text {nd }}$ Trimester & $3^{\text {rd }}$ Trimester & Never \\
\hline Oral examination & 1 & 2 & 3 & 4 \\
\hline Prophy & 1 & 2 & 3 & 4 \\
\hline Scaling and root planning & 1 & 2 & 3 & 4 \\
\hline Single periapical x-ray & 1 & 2 & 3 & 4 & 5 \\
\hline Full mouth x-rays \& panoramic radiograph & 1 & 2 & 3 & 4 & 5 \\
\hline Injection of local anesthetic (e.g., lidocaine) & 1 & 2 & 3 & 4 \\
\hline Single tooth extraction & 1 & 2 & 3 & 4 \\
\hline Amalgam restoration & 1 & 2 & 3 & 5 \\
\hline Composite restoration & 1 & 2 & 3 & 4 \\
\hline Root canal therapy & 1 & 2 & 3 & 4 \\
\hline Crown & 1 & 3 & 4 & 5 \\
\hline
\end{tabular}




\begin{tabular}{|l|l|l|l|l|l|}
\hline Nitrous oxide (30\%) & 1 & 2 & 3 & 4 & 5 \\
\hline Emergency & Anytime during pregnancy & $1^{\text {st }}$ Trimester & $2^{\text {nd }}$ Trimester & $3^{\text {rd }}$ Trimester & Never \\
\hline Single tooth extraction & 1 & 2 & 3 & 4 & 5 \\
\hline Injection of local anesthetic & 1 & 2 & 3 & 4 & 5 \\
\hline Incision and graining and abcess & 1 & 2 & 3 & 4 & 5 \\
\hline Open and broach & 1 & 2 & 3 & 4 & 5 \\
\hline Temporary filling & 1 & 2 & 3 & 4 & 5 \\
\hline
\end{tabular}

Do you believe it can be used safely during pregnancy with indication and supervision?

\begin{tabular}{|l|l|l|l|}
\hline Analgesics & Anytime during pregnancy & Short duration & Never \\
\hline Acetaminophen & 1 & 2 & 3 \\
\hline Non-steroidal, anti-inflammatory agents, NSAIDS (e.g., lbuprofen) & 1 & 2 & 3 \\
\hline Antibiotics & Anytime during pregnancy & Short duration & Never \\
\hline Amoxicillin & 1 & 2 & 3 \\
\hline Cephalosporins & 1 & 2 & 3 \\
\hline Clindamycin & 1 & 2 & 3 \\
\hline Metronidazole & 1 & 2 & 3 \\
\hline Ciprofloxacin & 1 & 2 & 3 \\
\hline Levofloxacin & 1 & 2 & 3 \\
\hline Moxifloxacin & 1 & 2 & 3 \\
\hline Clarithromycin & 1 & 2 & 3 \\
\hline Tetracycline & 1 & 2 & 3 \\
\hline Anesthetic & Anytime during pregnancy & Short duration & Never \\
\hline Local anesthetics with epinephrine (e.g., lidocaine) & 1 & 2 & 3 \\
\hline Nitrous oxide (30\%) & 1 & 2 & 3 \\
\hline Antimicrobials & Anytime during pregnancy & Short duration & Never \\
\hline Chlorhexidine (Without alcohol) & 1 & 2 & 3 \\
\hline Xylitol & 1 & 2 & 3 \\
\hline
\end{tabular}

*Short duration: 48-72 hours

How often do you prescribe the following pharmaceuticals for?

\begin{tabular}{|l|l|l|l|l|}
\hline & Often & Sometimes & Rarely & Never \\
\hline Non-steroidal, anti-inflammatory agents, NSAIDS (e.g., lbuprofen) & 1 & 2 & 3 & 4 \\
\hline Acetaminophen & 1 & 2 & 3 & 4 \\
\hline Chlorhexidine & 1 & 2 & 3 & 4 \\
\hline Oral Antibiotics & 1 & 2 & 3 & 4 \\
\hline
\end{tabular}


How often do you perform each of the following procedures on pregnant women?

\begin{tabular}{|l|l|l|l|}
\hline & Often & Sometimes & Rarely \\
\hline Oral examination & 1 & 2 & 3 \\
\hline Prophy & 1 & 2 & 4 \\
\hline Scaling and root planing & 1 & 2 & 3 \\
\hline Single periapical x-ray & 1 & 2 & 3 \\
\hline Full mouth x-rays \& panoramic radiograph & 1 & 2 & 3 \\
\hline Injection of local anesthetic & 1 & 2 & 3 \\
\hline Single tooth extraction & 1 & 3 & 4 \\
\hline Amalgam restoration & 1 & 3 & 4 \\
\hline Composite restoration & 1 & 2 & 4 \\
\hline Root canal therapy & 1 & 2 & 3 \\
\hline Crown & 1 & 2 & 3 \\
\hline Nitrous oxide (30\%) & 1 & 2 & 3 \\
\hline
\end{tabular}

\section{Education and Information}

\begin{tabular}{|c|c|c|c|c|c|}
\hline & $\begin{array}{l}\text { Strong } \\
\text { Agree }\end{array}$ & $\begin{array}{l}\text { Somewhat } \\
\text { Agree }\end{array}$ & $\begin{array}{l}\text { Neither } \\
\text { Agree/Disagree }\end{array}$ & $\begin{array}{l}\text { Somewhat } \\
\text { Disgree }\end{array}$ & $\begin{array}{l}\text { Strongly } \\
\text { Disagree }\end{array}$ \\
\hline $\begin{array}{l}\text { Interdisciplinary approach between OB/GYN and dentist } \\
\text { should be built }\end{array}$ & 1 & 2 & 3 & 4 & 5 \\
\hline $\begin{array}{l}\text { Information about a Continuing Ed program on care for } \\
\text { pregnant patients is needed }\end{array}$ & 1 & 2 & 3 & 4 & 5 \\
\hline
\end{tabular}

The survey questions drawn from an existing research instrument*. Some changes were made according to the current situation in China.

*Huebner C, Milgrom P, Conrad D, Lee R. Providing dental care to pregnant women: a survey of Oregon general dentists. J Am Dent Assoc. 2009;140:211-22. 